\title{
Modulating Co-Stimulation
}

\author{
Vissia Viglietta and Samia J. Khoury \\ Clinical Immunology Laboratory, Center for Neurologic Diseases, Brigham and Women's Hospital and Harvard Medical School, \\ Boston, MA 02115
}

\begin{abstract}
Summary: The modulation of co-stimulatory pathways represents a novel therapeutic strategy to regulate autoimmune diseases. Auto-reactive CD4 $+\mathrm{T}$ cells play a critical role in initiating the immune response leading to inflammation and autoimmune diseases. Blocking co-stimulatory signals prevents T-cell activation, thus diminishing autoimmune responses and possibly preventing the progression of autoimmune disease. Blockade of several co-stimulatory pathways has been investigated in animal models and has led to clinical trials testing specific blocking agents in humans. In this review we will describe the role of co-stimulatory pathways, primarily the
\end{abstract}

CD28-B7 pathway, in autoimmune diseases, and we will present in vivo and in vitro studies supporting the efficacy of co-stimulation blockade in animal models of autoimmune disease. Finally, we will discuss the clinical therapeutic efficacy of blocking monoclonal antibodies in preventing or reducing autoantigen driven T-cell activation in humans with particular attention to the $\mathrm{CD} 28 / \mathrm{B} 7$ pathway. Inhibiting co-stimulatory molecule interactions by using monoclonal antibodies seems to be an original approach to regulate autoimmune diseases in humans. Key Words: T-cell activation, CD28/B7 molecules, co-stimulation blockade, CTlA-4 Ig, EAE/MS, monoclonal antibody (mAb).

\section{INTRODUCTION}

Optimal antigen-specific activation of $\mathrm{T}$ cells requires two separate signals (FIG. 1). The first signal is specific and mediated through the T-cell receptor (TCR) recognizing the MHC-peptide complex. The second signal is co-stimulatory and is provided by both the cell-surface molecules displayed on antigen presenting cells (APC) and the soluble factors. The absence of a second signal promotes T-cell anergy, which is a state of antigenspecific nonresponsiveness due to the regulation of interleukin (IL)-2 production, which is a fundamental growth factor for T cells. ${ }^{1-5}$ The two-signal model oversimplifies the contribution of each signal because the strength of the TCR signal has a quantitative influence on T-cell activation and differentiation. ${ }^{6,7}$ Thus, T-cell activation can occur in the absence of signal 2 if the TCR signal is very strong. Several co-stimulatory signaling molecules have been described, and they generally belong to two families: 1) the B7 family ${ }^{8}$ and 2) the TNF family of receptors. ${ }^{9}$ In this review we focus mainly on

Address correspondence and reprint requests to: Vissia Viglietta, M.D., Ph.D., Center for Neurologic Diseases, Harvard Institutes of Medicine, \#714, 77 Avenue Louis Pasteur, Boston, MA 02115. E-mail: vviglietta@rics.bwh.harvard.edu. members of the B7 family (CD28:B7, PD-1:PD-1 ligands), on CD40-CD154 from the TNF family and on some other co-stimulatory molecules.

\section{Relevance of $\mathrm{CD28} / \mathrm{B} 7$ pathway in autoimmune diseases}

One of the major and better-characterized T-cell costimulatory pathways identified is the $\mathrm{CD} 28 / \mathrm{B} 7$ pathway. The engagement of $\mathrm{CD} 28$, expressed on $\mathrm{T}$ cells, with B7-1 and B7-2 (CD80 and CD86, respectively), expressed on APCs, is able to intensify the specific signal delivered through the TCR and promotes cell division and differentiation. ${ }^{1,3}$ Conversely the engagement of B7 molecules with the cytotoxic T-lymphocyte associated gene-4 (CTLA-4) receptor, predominantly expressed on activated $\mathrm{T}$ cells, delivers an inhibitory signal. ${ }^{10,11}$ The co-stimulation provided by $\mathrm{CD} 28$ seems to be essential in the induction of experimental autoimmune encephalitis (EAE), a murine model of multiple sclerosis (MS), and it is also involved in the recruitment of activated $\mathrm{T}$ cells to the site of the lesions after the clinical onset of the disease. Direct blockade of CD28 with anti-CD28 Fab fragments after disease onset was able to reduce disease severity. Similarly, anti-B7-1 prevented further relapses in EAE by inhibiting epitope spreading. ${ }^{12-15} \mathrm{~T}$ cells derived from mice deficient in CD28 were not able to 


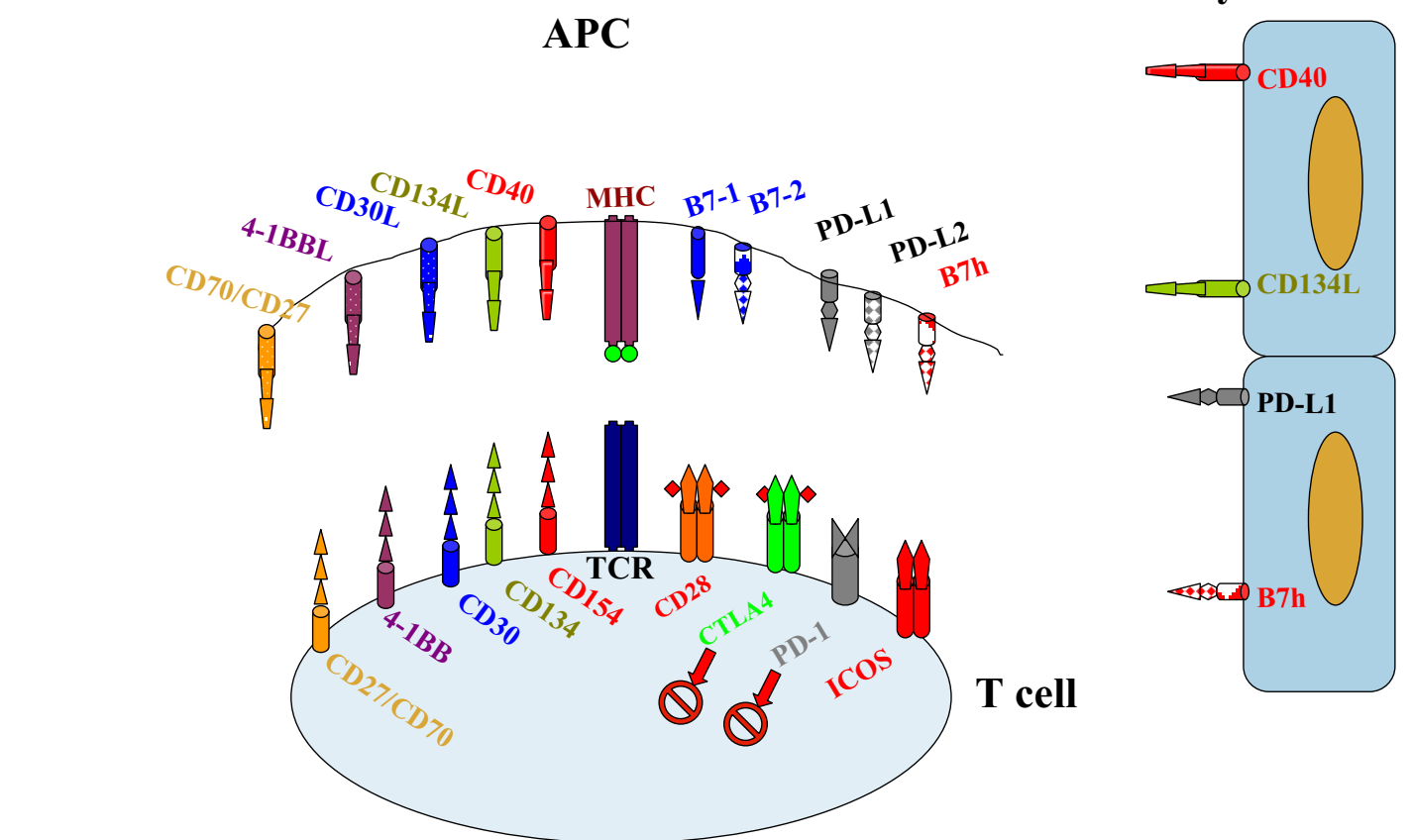

\section{Parenchymal cells}

FIG. 1. Schematic representation of co-stimulatory molecules. Signal 1 is represented by the T-cell receptor (TCR) interacting with the antigen in the MHC groove. The B7 family of co-stimulatory molecules is depicted to the right of the TCR, whereas the TNF family of receptors is depicted on the left. Some of the ligands are also expressed on parenchymal cells. Signals from the CTLA4 and PD-1 are inhibitory to the T cell. (1BB, CDw137; 1BBL, CDw137 ligand; CTLA-4, cytotoxic T-lymphocyte associated gene-4; ICOS, inducible co-stimulator; PD, programmed death.)

produce IL-2 in response to stimuli, although they efficiently released interferon- $\gamma$, the prototypical T-helper 1 cytokine.

B7-1 and B7-2 are differentially expressed on APCs showing different kinetics and distinct binding affinities. Although B7-2 is constitutively expressed on monocytes, B7-1 expression can be induced on activation. The B7 molecules seem to play an important role in the effector phase of EAE. Adoptive transfer of myelin oligodendrocyte glycoprotein specific $\mathrm{T}$ cells to B7-1/B7-2 deficient mice resulted in reduced EAE. ${ }^{16}$ In the CNS, B7 molecules are mostly expressed by $\mathrm{T}$ cells during the course of $\mathrm{EAE}^{17}$ and they interact differently with their ligands (CD28 and CTLA-4), leading to co-stimulation on CD28 binding or down-modulation in the case of CTLA-4 binding. Although B7-1 and B7-2 seem to have redundant functions, many studies showed a possible differential role for these molecules in initiating and regulating autoimmune diseases. ${ }^{18}$ In MS, B7-1 is preferentially expressed during disease activity, ${ }^{19,20}$ and it is associated with MS plaques and expressed on B cells during relapses. ${ }^{21}$ Different genetic backgrounds or the presence of different myelin antigens, as well as the avidity of T-cell interaction with the antigen-MHC complex, may determine the diverse role of B7-1 and B7-2.

\section{CO-STIMULATORY BLOCKADE IN EAE: AN ANIMAL MODEL OF MS}

The fundamental role of CD28/B7 co-stimulation has inspired the investigation of its role in animal models of organ-specific autoimmune diseases that are induced through the administration of self-proteins or single peptides. In these models, blockade of CD28 co-stimulation at the time of immunization reduced the severity of the disease or completely prevented it. ${ }^{22-24}$ Different approaches have been used to inhibit co-stimulation by targeting each of the molecules, CD28 on T cells or B7-1 and B7-2 on APC. Blocking CD28/B7 pathway at the time of disease induction showed efficacy in the prevention of disease in animal models of EAE, lupus and diabetes. ${ }^{25-27}$ Some of these studies concurrently showed decreased proliferative ability of the auto-reactive $T$ cells in lymph nodes, ${ }^{28}$ suggesting decreased expansion of $\mathrm{T}$ cells in vivo. Other mechanisms contributing to disease suppression were immune deviation by regulating the equilibrium of Th1 and Th2 cytokines, controlling T-cell migration or inducing anergy. ${ }^{14,29}$

EAE is an inflammatory disease of the CNS that can be induced in a number of species by immunization with myelin antigens or encephalitogenic peptides. It is the major animal model for the study of human MS, and has been studied extensively in rats, mice and guinea pigs. 
EAE is a T-cell-mediated disease, which is initiated by antigen-specific encephalitogenic CD4+ T cells. ${ }^{30,31} \mathrm{Al}-$ ternatively, EAE can be caused by adoptive transfer of $\mathrm{T}$ cells specific for myelin antigens, confirming the autoimmune nature of the disease. ${ }^{32,33}$ In vivo studies have shown a great variability among different strains of mice in the development of EAE after immunization ${ }^{34}$ with myelin antigens such as myelin basic protein (MBP) and proteolipid protein (PLP), the principal constituents of the myelin sheath and myelin oligodendrocyte glycoprotein. $^{35,36} \mathrm{~T}$ cells that are able to induce EAE are not deleted in the thymus, but they are part of the normal cell repertoire, suggesting that these typically quiescent cells may become pathogenic and cross the blood-brain barrier where they initiate an autoimmune response in the CNS. One of the factors driving activation of auto-reactive cells seems to be the co-stimulatory pathway.

Co-stimulatory molecules are differentially expressed during the various phases of EAE, which are likely due to genetic influences because there is also differential expression in various mouse strains. In the EAE model induced by myelin basic protein immunization, the expression of B7-2 was predominant during the acute phase or relapse, whereas B7-1 was found exclusively during remission. ${ }^{17,37} \mathrm{CD} 28$ was highly expressed during acute disease as well as during remission. In PLP-induced EAE, B7-1 was the molecule predominantly expressed during acute episodes of disease. ${ }^{37}$ Some studies have suggested that B7-1 and B7-2 might have distinct functions and favor Th1 or Th2 cytokines, respectively; although later studies did not confirm these findings. The discrepancy might be due to differential expression of B7 molecules at different times after activation or to differential expression on several cell types.

CTLA-4 is expressed on the T-cell surface after activation and binds B7-1 and B7-2 with higher avidity than CD28. CTLA-4Ig, a fusion protein comprising the extracellular domain of CTLA-4 with an Ig tail, blocks the interaction of CD28 with B7 molecules. When administered after adoptive transfer of pathogenic T cells, CTLA-4Ig delayed disease onset and decreased the severity of the clinical symptoms under certain experimental conditions. ${ }^{15,26}$ In other studies, CTLA-4Ig administration exacerbated the disease, ${ }^{10,38,39}$ demonstrating the complexity of the CD28/B7 system. It is possible that CTLA-4Ig is unable to enter the CNS and the inhibition of the CD28/B7 interaction should occur at the site of inflammation. One study demonstrated that whereas systemic treatment with CTLA-4Ig had only marginal effects on EAE, the local delivery of CTLA-4Ig by adenoviral vectors was effective in ameliorating disease. ${ }^{40}$ Other studies showed that anti-CD28 or CTLA4Ig used after the first clinical episode of disease, prevented additional relapses, thus suggesting that this approach may be useful even after the autoimmune disease is already established. ${ }^{41,42}$

The contradictory results derived from studies on costimulation highlight the complexity of the fine interactions among the different molecules at different stages of the disease and in different models of the disease.

\section{Other co-stimulatory pathways}

CD40/CD40L. Another recently characterized Tcell co-stimulatory pathway is the CD40/CD40L (CD154). CD40 molecules are expressed on the surface of APCs and B cells, and CD154 are expressed on the surface of activated T cells. ${ }^{43,44}$ CD40 may provide a direct co-stimulatory signal for full T-cell activation. There is also evidence that engagement of CD40 and CD154 leads to upregulation of B7 expression on APCs. ${ }^{45,46}$ The mechanisms of EAE inhibition by blockade of the CD28-B7 co-stimulatory pathway by the fusion protein CTLA4Ig or anti-B7 monoclonal antibodies (mAbs) have been investigated by several laboratories. ${ }^{12,14,26,47,48}$ Blockade of CD28-B7 or CD40-CD154 pathways was successful in preventing or ameliorating ongoing disease in numerous other autoimmune disease models. ${ }^{27,42,49-52}$ Furthermore, the approach of co-stimulatory signal blockade was successful in preventing transplant rejection. ${ }^{53,54}$

CTLA-4 plays a negative role in T-cell activation and represents a major regulator in the maintenance of peripheral tolerance. In fact, mice deficient for CTLA-4 develop fatal lymphoproliferative disorders. ${ }^{10,11}$ The administration of anti-CTLA-4Ab favors T-cell expansion and autoimmune reactivity. Studies both, in vivo and in vitro, have demonstrated that CTLA-4 has a role in Thelper regulation favoring Th2 differentiation and promoting the secretion of high levels of IL-4 and IL-5. Furthermore, CTLA- 4 seems to promote the expression of anti-apoptotic factors such as Bcl- $\mathrm{x}_{\mathrm{L}}$, playing a role in T-cell survival. ${ }^{55}$ Therapeutic approaches using activating antibodies may be considered in the future to exploit the natural down-regulatory activity of CTLA-4.

CD2/LFA3. Several other co-stimulatory molecules have been described. $\mathrm{CD} 2$, the T-cell rosette receptor expressed on mature $\mathrm{T}$ cells, is able to bind leukocyte function-associated antigen 3 (LFA-3) or CD58, providing a co-stimulatory signal. Many attempts have been made to interrupt this signal to induce immune suppression. A soluble LFA-3-IgG1 fusion protein binds to CD2 preventing its interaction with LFA-3 expressed on APCs. This drug has been tested in clinical trials in patients with psoriasis and was well tolerated and efficacious in the treatment of this disease. ${ }^{56}$

LFA-1/ICAM. LFA-1 is another cell-adhesion molecule expressed on the surface of monocytes, macrophages, neutrophils and lymphocytes that bind several intercellular adhesion molecules (ICAM-1, ICAM-2, 
ICAM-4 and ICAM-5) expressed on various cell subsets. The interactions between these molecules plays a key role in delivering co-stimulatory signals, recruiting cells to the site of inflammation and stabilizing the APC-T cell interaction. Trials on patients with psoriasis have shown that the monoclonal antibodies directed against LFA-1 ligands, such as ICAM-1 and ICAM-3, are effective in the treatment of the disease..$^{57-61}$

VLA-4. The very late antigen 4 (VLA-4), an adhesion molecule expressed on most leukocytes, comprises two different polypeptides (i.e., CD49d and CD29). Their binding to cell surface proteins such as MadCAM-1 and ICAM-4 favors the recruitment of cells to the site of inflammation and provides co-stimulatory signal to the T cells. Several different inhibitors of VLA-4 have been evaluated. The most successful was natalizumab, a humanized antibody directed against $\alpha_{4}$ integrin (CD49d) tested in MS, as well as Crohn's disease. ${ }^{62-64}$ Natalizumab was approved by the United States Food and Drug Administration for the treatment of MS based on its ability to significantly reduce the relapse rate in patients with relapsing-remitting MS. However, progressive multifocal leucoencephalopathy (PML) developed in two patients receiving natalizumab in combination with interferon-beta-1a. ${ }^{65,66} \mathrm{~A}$ third case of PML was identified in the Crohn's disease trial after a mistaken diagnosis of fatal astrocytoma. The analysis of frozen serum samples showed the presence of JC virus DNA three months after the initiation of the trial, and two months before the appearance of symptomatic PML. ${ }^{67}$ The use of natalizumab has been resumed as monotherapy in patients with MS who are intolerant or not responding to other treatments.

PD-1/PDL-1. Programmed death 1 (PD-1) and its ligands (PDL-1 and PDL-2) are new members of the B7 family of co-stimulatory molecules. PD-1 is expressed on activated $\mathrm{CD} 4+, \mathrm{CD} 8+, \mathrm{B}$ cells and myeloid cells but not on naïve cells. ${ }^{68}$ PDL-1 is constitutively expressed on freshly isolated splenic T cells, B cells, macrophages and dendritic cells. PDL-1 has also been detected in nonlymphoid organs in both mice and humans. ${ }^{69,70}$ The engagement of PD-1, with its ligand PDL-1, causes inhibition of anti-CD3-induced activation of $\mathrm{T}$ cells particularly in suboptimal co-stimulatory condition and when weak signals are provided to the TCR. ${ }^{71}$ The engagement of PDL-2 is also capable of reducing CD4+ T-cell activation and cytokine production after TCR stimulation. ${ }^{72}$ However, other reports indicate that the PD-1 pathway can provide a positive co-stimulatory signal inducing T-cell proliferation as well as cytokine production. ${ }^{73,74}$ The reasons for this discrepancy are unknown but could possibly be related to the existence of another ligand that delivers a positive signal to the $\mathrm{T}$ cell. It has been demonstrated that PD-1-deficient mice show increased $\mathrm{T}$ - and B-cell proliferation and higher predis- position to develop autoimmune diseases. ${ }^{75}$ In the spontaneous model of diabetes (nonobese diabetic [NOD], mouse) the blockade of PD-1 and PDL-1 caused precipitation of the disease, whereas PDL-2 did not have any effect. ${ }^{76}$ PD-1 blockade also triggered the onset of diabetes in male NOD mice that are normally resistant to the disease. PDL-1, but not PDL-2, was found expressed on inflamed pancreatic islets in NOD mice, suggesting a key role of this pathway in the induction and progression of autoimmune diabetes.

In the myelin oligodendrocyte glycoprotein-induced EAE model, blockade of PD-1, as well as PDL-2, provoked exacerbation of the disease and increased T-cell infiltration in the brain. ${ }^{77}$ Little is known about the PD-1 pathway in humans. Studies conducted on patients with rheumatoid arthritis (RA) have shown that PD-1 is highly expressed on the CD4 $+\mathrm{T}$ cells isolated from synovial fluid. These cells express high levels of CTLA-4 and are able to secrete high levels of IL-10. ${ }^{78}$ Several studies have demonstrated that PD-1 inhibition in CD28-deficient mice, normally resistant to EAE, induced worse disease than CTLA-4 blockade. ${ }^{79}$

In MS patients, the memory T lymphocytes subset had lower expression of PD- $1 .^{80} \mathrm{PD}-1$ is markedly upregulated on the surface of exhausted virus-specific CD8 $+\mathrm{T}$ cells during chronic viral infections, such as human immunodeficiency virus (HIV)-1 and chronic lymphocytic choriomeningitis virus. In treatment naïve HIV patients, upregulated PD-1 expression on HIV-specific CD8 + T cells correlated with impaired HIV-specific CD8 + T-cell function. PD-1 expression on these cells correlated with plasma viral load and inversely correlated with CD4+ T-cell count, which are predictors of disease progression. ${ }^{81}$ The correlations between PD-1 expression and clinical outcome were recently strengthened by the finding that long-term HIV nonprogressors exhibited functional HIV-specific memory CD8 + T cells with markedly lower PD-1 expression, whereas typical progressors showed upregulated PD-1 expression correlating with a reduction in CD4 T-cell number and increased plasma viral load. ${ }^{82}$ Furthermore, PD-1 upregulation was associated with reduced perforin and interferon-gamma production, as well as decreased HIV-specific effector memory CD8 $+\mathrm{T}$-cell proliferation in progressors. Blockade of this pathway reinvigorates the exhausted $\mathrm{T}$ cells, allowing them to expand and produce effector cytokines and reduce viral load. ${ }^{82-85}$

Given the essential role of co-stimulation in the activation of pathogenic $\mathrm{T}$ cells, the development of therapeutic strategies aiming at the selective blockade of costimulatory molecules has been a focal point of studies of autoimmune diseases. Blockade of co-stimulation would in fact have the advantage of targeting those $\mathrm{T}$ cells that have already received the first signal regardless of the specific antigen triggering the TCR. 
TABLE 1. Antibody Therapies in Humans

\begin{tabular}{|c|c|c|c|}
\hline Treatment & Target Molecule & Results & References \\
\hline Abatacept & B71/B72 & Improves RA and psoriasis & $\begin{array}{l}\text { Moreland, et al. } 2002(106) \\
\text { Kremer, et al. } 2005(112) \\
\text { Abrams, et al. } 2000(114)\end{array}$ \\
\hline Belatacept & B71/B72 & Prevents acute renal transplant rejection & Vincenti, et al. 2005 (115) \\
\hline Natalizumab & VLA-4 & Improves MS and Crohn's disease & $\begin{array}{l}\text { Gordon, et al. } 2001 \text { (62) } \\
\text { von Andrian, et al. } 2003 \text { (63) } \\
\text { Polman, et al. } 2006 \text { (64) }\end{array}$ \\
\hline Anti-PD-1 & PD-1 & $\begin{array}{l}\text { Reinvigorates exhausted T cells in LCMV } \\
\text { and HIV }\end{array}$ & $\begin{array}{l}\text { Freeman, et al. } 2006 \text { (83) } \\
\text { Trautmann, et al. } 2006(84) \\
\text { Petrovas, et al. } 2006(85) \\
\text { Zhang, et al. } 2007 \text { (82) }\end{array}$ \\
\hline Anti-CD154 & CD40-L & $\begin{array}{l}\text { SLE and MS trials halted because of } \\
\text { thromboembolic events }\end{array}$ & Nakamura, et al. 2006 (123) \\
\hline SGN-40 & CD40 & $\begin{array}{l}\text { Currently in clinical trial for the treatment } \\
\text { of B-cell neoplasias }\end{array}$ & $\begin{array}{l}\text { Tai, et al. } 2005(125) \\
\text { Kelley, et al. } 2006(124)\end{array}$ \\
\hline
\end{tabular}

Abbreviations: PD, programmed death; LCMV, lymphocytic choriomeningitis virus; MS, multiple sclerosis; RA, rheumatoid arthritis; SLE, systemic lupus erythematosus; SGN-40, humanized anti-CD40; VLA, very late antigen.

\section{CO-STIMULATION DEPENDENCE OF NAÏVE AND MEMORY T CELLS}

Several studies have shown that naïve $\mathrm{T}$ cells derived from TCR transgenic mice are fully dependent on the CD28/B7 co-stimulation to proliferate against specific antigens. ${ }^{86-89}$ Conversely, inhibiting CD28/B7 interactions result in decreased proliferation and decreased number of activated cells divisions. ${ }^{90,91}$ CD28, in fact, is important for the transcription of IL-2, ${ }^{5,92}$ an essential T-cell growth factor; it promotes the expression of $\mathrm{Bcl}-\mathrm{x}_{\mathrm{L}}$, an anti-apoptotic proteinsustaining cell survival both in vivo and in vitro, ${ }^{93-96}$ and reduces the threshold of T-cell activation. ${ }^{6}$ T-cell surface molecules are also adhesion molecules playing an important role in the stabilization of the immunological synapse. ${ }^{97}$

Unlike naïve $\mathrm{T}$ cells, primed as well as memory $\mathrm{T}$ cells are less dependent on co-stimulation, ${ }^{98-101}$ probably due to the expression of lck, which favors a lower threshold for T-cell activation. It has been shown that the expansion of auto-reactive T cells in MS is independent of exogenous B7 co-stimulation. It has also been demonstrated that in patients with MS, myelin basic protein reactive $\mathrm{T}$ cells are less dependent on $\mathrm{CD} 28$ co-stimulation indicating a different state of activation of potentially pathogenic T cells. ${ }^{101}$ The dependency on CD28 co-stimulation is also related to the strength of the signal delivered to the cells. T-cell activation induced by weak agonists or antigens provided at low concentration is dependent on co-stimulation. ${ }^{102}$ Conversely, if strong agonists are available or high amounts of specific antigens are provided, the requirement for co-stimulation notably decreases. ${ }^{98,101,103}$

\section{CO-STIMULATORY BLOCKADE TREATMENTS IN HUMAN AUTOIMMUNE DISEASES}

In humans, one of the better characterized co-stimulatory blocking agents is CTLA-4Ig (see Table 1). CTLA-4Ig is able to bind B7-1 and B7-2 on APC, thus inhibiting their engagement to $\mathrm{CD} 28$ on $\mathrm{T}$ cells. In preclinical studies CTLA-4Ig was effective in preventing or reducing the severity of different autoimmune diseases in animal models as well as in humans ${ }^{27,104-106}$ and in inducing islet transplant tolerance. ${ }^{107}$ Despite these beneficial effects, CTLA-4Ig has also been shown to increase immunity under some circumstances in animals. CTLA-4Ig might in fact prevent the engagement of the negative regulator CTLA-4 promoting increased T-cell activation. ${ }^{108} \mathrm{An}$ additional reason explaining the dual effect of CTLA-4Ig is related to regulatory cells. Regulatory $\mathrm{T}$ cells are indeed dependent on CD28 for their development and survival, thus the use of CTLA-4Ig can induce a drastic reduction of this cell population and exacerbate the autoimmune process. ${ }^{109,110}$ Despite the intricacies of co-stimulatory modulation, CTLA-4Ig has been developed and tested in patients with autoimmune diseases.

CTLA-4Ig was evaluated in humans for the treatment of rheumatoid arthritis (RA). A placebo-controlled study evaluated two different doses ( 2 or $10 \mathrm{mg} / \mathrm{kg}$ of body weight) of the fusion protein in more that 100 patients per group during a six-month period. CTLA-4Ig was efficacious in improving the signs and symptoms of RA and inhibiting the radiographic progression of the disease. According to criteria established by the American College of Rheumatology, significant improvements 
were found only in the group treated with the highest dose of CTLA-4Ig, whereas the group treated with $2 \mathrm{mg}$ of CTLA-4Ig was not considerably different from the placebo group. ${ }^{106}$ A phase III study has also been conducted on patients with RA receiving methotrexate. The combination of methotrexate and CTLA-4Ig treatment showed significant, dose-dependent improvement in signs and symptoms of RA, as well as in quality of life of patients with active disease. ${ }^{111,112}$ In light of these favorable results, CTLA-4Ig (abatacept) has been approved by the United States Food and Drug Administration for the treatment of RA.

CTLA-4Ig has been tested in patients with psoriasis, a $\mathrm{T}$-cell-mediated skin disorder, in a phase I, open-label, dose-escalation trial. ${ }^{113}$ Its effect on both T-cell co-stimulation and humoral responses to T-cell-dependent antigens was evaluated. Four infusions of CTLA-4Ig were given to 40 patients with stable disease. Forty-six percent of the patients, mainly in the highest dose cohorts, showed sustained clinical improvement. Reduction of epidermal hyperplasia correlating with a decrease in $\mathrm{T}$ cell infiltrates and diminished epidermal proliferation were also observed. ${ }^{114}$ No increase in T-cell apoptosis was identified in the skin lesions, suggesting that the decreased number of $\mathrm{T}$ cells was due to reduced proliferation and recruitment of T cells. CTLA-4Ig therapy did not induce long-term tolerance to T-cell dependent neoantigens. Patients treated with CTLA-4Ig and immunized with two different neo-antigens (i.e., bacteriophage X174 and KLH immune activator) showed suppression of antibody titers only after the first two immunizations. Immune responses developed in most of the patients at the following immunizations, showing lack of permanent tolerance to these neo-antigens.

Belatacept (LEA29Y) differs from abatacept by substitution of two amino acids, which confers a stronger binding avidity to $\mathrm{B} 7$ and a greater inhibition of T-cell activation. The treatment with belatacept was as effective as cyclosporine in preventing acute rejection after renal transplant rejection and in helping preserve glomerular filtration rate, as measured by iohexol plasma clearance. $^{115}$

MS is another T-cell-mediated disease in which costimulation seems critical to the initiation, as well as progression of the inflammatory process. The disease is characterized by the presence of perivascular, inflammatory infiltrates that lead to demyelination, traits also characteristic of EAE. ${ }^{116,117}$

Auto-reactive $\mathrm{T}$ cells are present in the peripheral circulation of both patients with MS and healthy individuals, ${ }^{118}$ but only in the patients these cells are able to cross the blood-brain barrier and initiate the inflammatory process. MBP-reactive T cells derived from patients with MS are less dependent on B7-costimulation compared to cells from healthy individuals, and this can be expanded in vitro in the presence of blocking anti-CD28 monoclonal antibodies. The different requirement for B7 co-stimulation suggests that memory cells that are chronically exposed to CNS auto-antigens are in a different state of activation compared to cells from healthy individuals. $^{101}$

A phase I, dose-escalation study to evaluate the safety and tolerability of CTLA-4Ig in patients with relapsingremitting MS was completed at the Partners Multiple Sclerosis Center (Boston, MA). We evaluated the disease-specific safety of a single infusion of CTLA-4 Ig in patients with relapsing-remitting MS, as well as the effects on immune functions of these patients. The drug was well tolerated by patients at the different doses of the fusion protein. A group of subjects received four doses of CTLA4Ig that were also well tolerated.

Blockade of CD40-CD154 interaction is effective in preventing the induction of several autoimmune diseases in animal models of thyroiditis, arthritis, diabetes and oophoritis. ${ }^{49,119-121}$ Both the initiation and the progression of EAE were inhibited by anti-CD154 controlling the expansion or the migration of Th1 pathogenic cells. $^{122}$ Unfortunately, studies in humans have not achieved the same success. Anti-CD154 trials were initiated in several autoimmune diseases, including a phase I study in MS, but the trials were all halted after the occurrence of thromboembolic events in lupus patients, probably due to reactivity of the monoclonal antibody with CD40L expressed on the surface of activated platelets. ${ }^{123}$

CD40 is expressed in B-cell malignancies and multiple solid tumors raising interest in its potential use as a target for antibody-based cancer therapy. SGN-40, a humanized monoclonal anti-CD40 antibody, inhibits B-cell tumor growth in vitro by mediating antibody-dependent cytotoxicity. ${ }^{124}$

SGN-40 has been shown to enhance the cytotoxic effect of lenalidomide against multiple myeloma (MM) cells by enhancing NK-cell-mediated lysis and upregulating $\mathrm{CD} 40 \mathrm{~L}$ on $\mathrm{CD} 56(+) \mathrm{CD} 3(-) \mathrm{NK}$ cells. ${ }^{125,126}$ Stimulation through CD40 on mouse and human renal cell carcinomas promotes cytokine production and leukocyte recruitment, enhancing immune responses, and thus anti-tumor activity. ${ }^{127}$

\section{CONCLUSIONS}

Co-stimulatory pathways play a fundamental role in the initiation and progression of autoimmune diseases, by controlling T-cell activation. Several strategies aimed at blocking co-stimulatory pathways have been developed and tested both in animal models and humans. Unlike previous therapies targeting all $\mathrm{T}$ cells, co-stimulation-blocking therapies affect activated $\mathrm{T}$ cells and thus may target potentially pathogenic cells. These treat- 
ments have shown better clinical efficacy and reduced side effects in patients with $\mathrm{T}$ cell-mediated autoimmune diseases. The successful results of CTLA-4Ig therapy in RA have inspired additional studies and suggest the potential use of this drug in other autoimmune disorders such as lupus and MS. Further investigations will be necessary to explore the mechanisms through which costimulatory blocking drugs exert their effects in humans. Animal studies have shown higher efficacy with the use of combination therapies using more than one blocking agent at once. Nevertheless, given the complexity of the co-stimulatory pathways we have to be cognizant of possible consequences of long-term therapy. It is unclear whether patients treated with co-stimulatory blocking agents will become more susceptible to opportunistic infections, particularly when used in combination therapies. However, data from the agents already in use do not suggest increased risk of infections and raise optimism for the future development of co-stimulation regulatory treatments.

Acknowledgments: This work is supported by research grants from the National Multiple Sclerosis Society (RG3666, RG2988 to SJK) and the National Institute of Health (AI058680 AI043496 and U19 AI046130 to SJK), and the Nancy Davis Center Without Walls.

\section{REFERENCES}

1. Harding FA, McArthur JG, Gross JA, Raulet DH, Allison JP. CD28-mediated signalling co-stimulates murine $\mathrm{T}$ cells and prevents induction of anergy in T-cell clones. Nature 1992;356:607609.

2. DeSilva DR, Urdahl KB, Jenkins MK. Clonal anergy is induced in vitro by $\mathrm{T}$ cell receptor occupancy in the absence of proliferation. J Immunol 1991;147:3261-3267.

3. Jenkins MK, Taylor PS, Norton SD, Urdahl KB. CD28 delivers a costimulatory signal involved in antigen-specific IL-2 production by human T cells. J Immunol 1991;147:2461-2466.

4. Ramsdell F, Jenkins M, Dinh Q, Fowlkes BJ. The majority of CD4+8- thymocytes are functionally immature. J Immunol 1991; 147:1779-1785.

5. Norton SD, Hovinen DE, Jenkins MK. IL-2 secretion and T cell clonal anergy are induced by distinct biochemical pathways. J Immunol 1991;146:1125-1129.

6. Viola A, Lanzavecchia A. T cell activation determined by T cell receptor number and tunable thresholds. Science 1996;273:104106.

7. Sloan-Lancaster J, Evavold BD, Allen PM. Induction of T-cell anergy by altered T-cell-receptor ligand on live antigen-presenting cells. Nature 1993;363:156-159.

8. Greenwald RJ, Freeman GJ, Sharpe AH. The B7 family revisited. Annu Rev Immunol 2005;23:515-548.

9. Watts TH. TNF/TNFR family members in costimulation of T cell responses. Annu Rev Immunol 2005;23:23-68.

10. Perrin PJ, Maldonado JH, Davis TA, June $\mathrm{CH}$, Racke MK. CTLA-4 blockade enhances clinical disease and cytokine production during experimental allergic encephalomyelitis. J Immunol 1996;157:1333-1336.

11. Krummel MF, Allison JP. CTLA-4 engagement inhibits IL-2 accumulation and cell cycle progression upon activation of resting T cells. J Exp Med 1996;183:2533-2540.

12. Cross AH, Girard TJ, Giacoletto KS, et al. Long-term inhibition of murine experimental autoimmune encephalomyelitis using
CTLA-4-Fc supports a key role for CD28 costimulation. J Clin Invest 1995;95:2783-2789.

13. Miller SD, Vanderlugt CL, Lenschow DJ, et al. Blockade of CD28/B7-1 interaction prevents epitope spreading and clinical relapses of murine EAE. Immunity 1995;3:739-745.

14. Kuchroo VK, Das MP, Brown JA, et al. B7-1 and B7-2 costimulatory molecules activate differentially the Th1/Th2 developmental pathways: application to autoimmune disease therapy. Cell 1995;80:707-718

15. Racke MK, Scott DE, Quigley L, et al. Distinct roles for B7-1 (CD-80) and B7-2 (CD-86) in the initiation of experimental allergic encephalomyelitis. J Clin Invest 1995;96:2195-2203.

16. Chang TT, Jabs C, Sobel RA, Kuchroo VK, Sharpe AH. Studies in B7-deficient mice reveal a critical role for B7 costimulation in both induction and effector phases of experimental autoimmune encephalomyelitis. J Exp Med 1999;190:733-740.

17. Issazadeh S, Navikas V, Schaub M, Sayegh M, Khoury S. Kinetics of expression of costimulatory molecules and their ligands in murine relapsing experimental autoimmune encephalomyelitis in vivo. J Immunol 1998;161:1104-1112.

18. Gallon L, Chandraker A, Issazadeh S, et al. Differential effects of B7-1 blockade in the rat experimental autoimmune encephalomyelitis model. J Immunol 1997;159:4212-4216.

19. Williams K, Ulvestad E, Antel JP. B7/BB-1 antigen expression on adult human microglia studied in vitro and in situ. Eur J Immunol 1994;24:3031-3037.

20. Windhagen A, Newcombe J, Dangond F, et al. Expression of costimulatory molecules B7-1 (CD80), B7-2 (CD86), and interleukin 12 cytokine in multiple sclerosis lesions. J Exp Med 1995; 182:1985-1996.

21. Genc K, Dona DL, Reder AT. Increased CD80(+) B cells in active multiple sclerosis and reversal by interferon beta- $1 \mathrm{~b}$ therapy. J Clin Invest 1997;99:2664-2671.

22. Peterson KE, Sharp GC, Tang H, Braley-Mullen H. B7.2 has opposing roles during the activation versus effector stages of experimental autoimmune thyroiditis. J Immunol 1999;162: $1859-1867$.

23. Bachmaier K, Pummerer C, Shahinian A, et al. Induction of autoimmunity in the absence of CD28 costimulation. J Immunol 1996;157:1752-1757.

24. Tada Y, Nagasawa K, Ho A, et al. CD28-deficient mice are highly resistant to collagen-induced arthritis. J Immunol 1999;162:203208.

25. Lenschow DJ, Ho SC, Sattar H, et al. Differential effects of anti-B7-1 and anti-B7-2 monoclonal antibody treatment on the development of diabetes in the nonobese diabetic mouse. J Exp Med 1995;181:1145-1155.

26. Perrin PJ, Scott D, Quigley L, et al. Role of B7:CD28/CTLA-4 in the induction of chronic relapsing experimental allergic encephalomyelitis. J Immunol 1995;154:1481-1490.

27. Finck BK, Linsley PS, Wofsy D. Treatment of murine lupus with CTLA4Ig. Science 1994;265:1225-1227.

28. Oliveira-dos-Santos AJ, Ho A, Tada Y, et al. CD28 costimulation is crucial for the development of spontaneous autoimmune encephalomyelitis. J Immunol 1999;162:4490-4495.

29. Girvin AM, Dal Canto MC, Rhee L, et al. A critical role for B7/CD28 costimulation in experimental autoimmune encephalomyelitis: a comparative study using costimulatory molecule-deficient mice and monoclonal antibody blockade. J Immunol 2000; 164:136-143.

30. Ben-Nun A, Wekerle H, Cohen IR. The rapid isolation of clonable antigen-specific $\mathrm{T}$ lymphocyte lines capable of mediating autoimmune encephalomyelitis. Eur J Immunol 1981;11:195.

31. Vandenbark AA, Gill T, Offner H. A myelin basic protein-specific $\mathrm{T}$ lymphocyte line that mediates experimental autoimmune encephalomyelitis. J Immunol 1985;153:223.

32. Zamvil SS, Steinman L. The T lymphocyte in experimental allergic encephalomyelitis. Annu Rev Immunol 1990;8:579-621.

33. Lublin FD, Whitaker JN, Eidelman BH, Miller AE, Arnason BG, Burks JS. Management of patients receiving interferon beta- $1 \mathrm{~b}$ for multiple sclerosis: report of a consensus conference. Neurology 1996;46:12-18. 
34. Ota K, Matsui M, Milford EL, Mackin GA, Weiner HL, Hafler DA. T-cell recognition of an immunodominant myelin basic protein epitope in multiple sclerosis. Nature 1990;346:183-187.

35. Fritz RB, McFarlin DE. Encephalitogenic epitopes of myelin basic protein. Chem Immunol 1989;46:101-125.

36. Martin R, McFarland HF, McFarlin DE. Immunological aspects of demyelinating diseases. Annu Rev Immunol 1992;10:153-187.

37. Karandikar NJ, Vanderlugt CL, Eagar T, Tan L, Bluestone JA, Miller SD. Tissue-specific up-regulation of B7-1 expression and function during the course of murine relapsing experimental autoimmune encephalomyelitis. J Immunol 1998;161:192-199.

38. Karandikar NJ, Vanderlugt CL, Walunas TL, Miller SD, Bluestone JA. CTLA-4: a negative regulator of autoimmune disease. J Exp Med 1996;184:783-788.

39. Hurwitz AA, Sullivan TJ, Krummel MF, Sobel RA, Allison JP. Specific blockade of CTLA-4/B7 interactions results in exacerbated clinical and histologic disease in an actively-induced model of experimental allergic encephalomyelitis. J Neuroimmunol 1997;73:57-62.

40. Croxford JL, O'Neill JK, Ali RR, et al. Local gene therapy with CTLA4-immunoglobulin fusion protein in experimental allergic encephalomyelitis. Eur J Immunol 1998;28:3904-3916.

41. Perrin PJ, June CH, Maldonado JH, Ratts RB, Racke MK. Blockade of CD28 during in vitro activation of encephalitogenic T cells or after disease onset ameliorates experimental autoimmune encephalomyelitis. J Immunol 1999;163:1704-1710.

42. Schaub M, Issazadeh S, Stadlbauer TH, Peach R, Sayegh MH, Khoury SJ. Costimulatory signal blockade in murine relapsing experimental autoimmune encephalomyelitis. J Neuroimmunol 1999;96:158-166.

43. Noelle RJ, Ledbetter JA, Aruffo A. CD40 and its ligand, an essential ligand-receptor pair for thymus-dependent B-cell activation. Immunol Today 1992;13:431-433.

44. Marshall LS, Aruffo A, Ledbetter JA, Noelle RJ. The molecular basis for T cell help in humoral immunity: CD40 and its ligand, gp39. J Clin Immunol 1993;13:165-174.

45. Klaus GG, Choi MS, Holman M. Properties of mouse CD40. Ligation of CD40 activates B cells via a $\mathrm{Ca}(++)$-dependent, FK506-sensitive pathway. Eur J Immunol 1994;24:3229-3232.

46. Caux C, Massacrier C, Vanbervliet B, et al. Activation of human dendritic cells through CD40 cross-linking. J Exp Med 1994;180: 1263-1272.

47. Khoury SJ, Akalin E, Chandraker A, et al. CD28-B7 costimulatory blockade by CTLA4Ig prevents actively induced experimental autoimmune encephalomyelitis and inhibits Th1 but spares Th2 cytokines in the central nervous system. J Immunol 1995; 155:4521-4524.

48. Schaub M, Stadlbauer TH, Sayegh MH. CTLA4Ig: effects on cellular and humoral immunity and macrophage activation. Exp Nephrol 1997;5:370-374.

49. Durie FH, Fava RA, Foy TM, Aruffo A, Ledbetter JA, Noelle RJ. Prevention of collagen-induced arthritis with an antibody to gp39, the ligand for CD40. Science 1993;261:1328-1330.

50. Early GS, Zhao W, Burns CM. Anti-CD40 ligand antibody treatment prevents the development of lupus-like nephritis in a subset of New Zealand black x New Zealand white mice. Response correlates with the absence of an anti-antibody response. J Immunol 1996;157:3159-3164.

51. Daikh DI, Finck BK, Linsley PS, Hollenbaugh D, Wofsy D. Long-term inhibition of murine lupus by brief simultaneous blockade of the B7/CD28 and CD40/gp39 costimulation pathways. J Immunol 1997;159:3104-3108.

52. Herold KC, Lu J, Rulifson I, et al. Regulation of C-C chemokine production by murine $\mathrm{T}$ cells by $\mathrm{CD} 28 / \mathrm{B} 7$ costimulation. $\mathrm{J}$ Immunol 1997;159:4150-4153.

53. Sayegh MH, Turka LA. T cell costimulatory pathways: promising novel targets for immunosuppression and tolerance induction. J Am Soc Nephrol 1995;6:1143-1150.

54. Khoury S, Sayegh MH, Turka LA. Blocking costimulatory signals to induce transplantation tolerance and prevent autoimmune disease. Int Rev Immunol 1999;18:185-199.

55. Walunas TL, Lenschow DJ, Bakker CY, et al. CTLA-4 can function as a negative regulator of $\mathrm{T}$ cell activation. Immunity 1994;1:405-413.

56. Ellis CN, Krueger GG. Treatment of chronic plaque psoriasis by selective targeting of memory effector $\mathrm{T}$ lymphocytes. N Engl J Med 2001;345:248-255.

57. Van Seventer GA, Shimizu Y, Horgan KJ, Shaw S. The LFA-1 ligand ICAM-1 provides an important costimulatory signal for T cell receptor-mediated activation of resting $\mathrm{T}$ cells. J Immunol 1990;144:4579-4586.

58. Dustin ML, Springer TA. T-cell receptor cross-linking transiently stimulates adhesiveness through LFA-1. Nature 1989;341:619624.

59. Staunton DE, Dustin ML, Springer TA. Functional cloning of ICAM-2, a cell adhesion ligand for LFA-1 homologous to ICAM-1. Nature 1989;339:61-64.

60. Krueger J, Gottlieb A, Miller B, Dedrick R, Garovoy M, Walicke P. Anti-CD11a treatment for psoriasis concurrently increases circulating T-cells and decreases plaque T-cells, consistent with inhibition of cutaneous T-cell trafficking. J Invest Dermatol 2000; 115:333.

61. Gottlieb A, Krueger JG, Bright R, et al. Effects of administration of a single dose of a humanized monoclonal antibody to CD11a on the immunobiology and clinical activity of psoriasis. J Am Acad Dermatol 2000;42:428-435.

62. Gordon FH, Lai CW, Hamilton MI, et al. A randomized placebocontrolled trial of a humanized monoclonal antibody to alpha4 integrin in active Crohn's disease. Gastroenterology 2001;121: $268-274$

63. von Andrian UH, Engelhardt B. Alpha4 integrins as therapeutic targets in autoimmune disease. N Engl J Med 2003;348:68-72.

64. Polman CH, O'Connor PW, Havrdova E, et al. A randomized, placebo-controlled trial of natalizumab for relapsing multiple sclerosis. N Engl J Med 2006;354:899-910.

65. Langer-Gould A, Atlas SW, Green AJ, Bollen AW, Pelletier D. Progressive multifocal leukoencephalopathy in a patient treated with natalizumab. N Engl J Med 2005;353:375-381.

66. Kleinschmidt-DeMasters BK, Tyler KL. Progressive multifocal leukoencephalopathy complicating treatment with natalizumab and interferon beta-1a for multiple sclerosis. N Engl J Med 2005; 353:369-374.

67. Van Assche G, Van Ranst M, Sciot R, et al. Progressive multifocal leukoencephalopathy after natalizumab therapy for Crohn's disease. N Engl J Med 2005;353:362-368.

68. Agata Y, Kawasaki A, Nishimura H, et al. Expression of the PD-1 antigen on the surface of stimulated mouse T and B lymphocytes. Int Immunol 1996;8:765-772.

69. Liang SC, Latchman YE, Buhlmann JE, et al. Regulation of PD-1, PD-L1, and PD-L2 expression during normal and autoimmune responses. Eur J Immunol 2003;33:2706-2716.

70. Rodig N, Ryan T, Allen JA, et al. Endothelial expression of PD-L1 and PD-L2 down-regulates CD8 $+\mathrm{T}$ cell activation and cytolysis. Eur J Immunol 2003;33:3117-3126.

71. Freeman GJ, Long AJ, Iwai Y, et al. Engagement of the PD-1 immunoinhibitory receptor by a novel B7 family member leads to negative regulation of lymphocyte activation. J Exp Med 2000; 192:1027-1034.

72. Latchman Y, Wood CR, Chernova T, et al. PD-L2 is a second ligand for PD-1 and inhibits $\mathrm{T}$ cell activation. Nat Immunol 2001;2:261-268.

73. Tseng SY, Otsuji M, Gorski K, et al. B7-DC, a new dendritic cell molecule with potent costimulatory properties for T cells. J Exp Med 2001;193:839-846.

74. Dong H, Zhu G, Tamada K, Chen L. B7-H1, a third member of the B7 family, co-stimulates T-cell proliferation and interleukin-10 secretion. Nat Med 1999;5:1365-1369.

75. Nishimura H, Nose M, Hiai H, Minato N, Honjo T. Development of lupus-like autoimmune diseases by disruption of the PD-1 gene encoding an ITIM motif-carrying immunoreceptor. Immunity 1999;11:141-151.

76. Ansari MJ, Salama AD, Chitnis T, et al. The programmed death-1 (PD-1) pathway regulates autoimmune diabetes in nonobese diabetic (NOD) mice. J Exp Med 2003;198:63-69. 
77. Salama AD, Chitnis T, Imitola J, et al. Critical role of the programmed death-1 (PD-1) pathway in regulation of experimental autoimmune encephalomyelitis. J Exp Med 2003;198:71-78.

78. Hatachi S, Iwai Y, Kawano S, et al. CD4+ PD-1+ T cells accumulate as unique anergic cells in rheumatoid arthritis synovial fluid. J Rheumatol 2003;30:1410-1419.

79. Chitnis T, Najafian N, Abdallah KA, et al. CD28-independent induction of experimental autoimmune encephalomyelitis. J Clin Invest 2001;107:575-583.

80. Krakauer M, Sorensen PS, Sellebjerg F. CD4(+) memory T cells with high CD26 surface expression are enriched for Th1 markers and correlate with clinical severity of multiple sclerosis. J Neuroimmunol 2006;181:157-164.

81. Day CL, Kaufmann DE, Kiepiela P, et al. PD-1 expression on HIV-specific $\mathrm{T}$ cells is associated with $\mathrm{T}$-cell exhaustion and disease progression. Nature 2006;443:350-354.

82. Zhang JY, Zhang Z, Wang X, et al. PD-1 up-regulation is correlated with HIV-specific memory CD8 + T-cell exhaustion in typical progressors but not in long-term nonprogressors. Blood 2007; 109:4671-4678.

83. Freeman GJ, Wherry EJ, Ahmed R, Sharpe AH. Reinvigorating exhausted HIV-specific T cells via PD-1-PD-1 ligand blockade. J Exp Med 2006;203:2223-2227.

84. Trautmann L, Janbazian L, Chomont N, et al. Upregulation of PD-1 expression on HIV-specific CD8 + T cells leads to reversible immune dysfunction. Nat Med 2006;12:1198-1202.

85. Petrovas C, Casazza JP, Brenchley JM, et al. PD-1 is a regulator of virus-specific CD8 $+\mathrm{T}$ cell survival in HIV infection. J Exp Med 2006;203:2281-2292.

86. Lucas PJ, Negishi I, Nakayama K, Fields LE, Loh DY. Naive CD28-deficient $\mathrm{T}$ cells can initiate but not sustain an in vitro antigen-specific immune response. J Immunol 1995;154:57575768 .

87. Walunas TL, Sperling AI, Khattri R, Thompson CB, Bluestone JA. CD28 expression is not essential for positive and negative selection of thymocytes or peripheral $\mathrm{T}$ cell tolerance. J Immunol 1996;156:1006-1013.

88. Sperling AI, Auger JA, Ehst BD, Rulifson IC, Thompson CB, Bluestone JA. CD28/B7 interactions deliver a unique signal to naive $\mathrm{T}$ cells that regulates cell survival but not early proliferation. J Immunol 1996;157:3909-3917.

89. Bachmann MF, McKall-Faienza K, Schmits R, et al. Distinct roles for LFA-1 and CD28 during activation of naive T cells: adhesion versus costimulation. Immunity 1997;7:549-557.

90. Wells AD, Gudmundsdottir H, Turka LA. Following the fate of individual $\mathrm{T}$ cells throughout activation and clonal expansion. Signals from $\mathrm{T}$ cell receptor and CD28 differentially regulate the induction and duration of a proliferative response. J Clin Invest 1997; 100:3173-3183.

91. Gudmundsdottir H, Wells AD, Turka LA. Dynamics and requirements of $\mathrm{T}$ cell clonal expansion in vivo at the single-cell level: effector function is linked to proliferative capacity. J Immunol 1999; 162:5212-5223.

92. Fraser JD, Irving BA, Crabtree GR, Weiss A. Regulation of interleukin-2 gene enhancer activity by the T cell accessory molecule CD28. Science 1991;251:313-316.

93. Judge TA, Wu Z, Zheng XG, Sharpe AH, Sayegh MH, Turka LA. The role of CD80, CD86, and CTLA4 in alloimmune responses and the induction of long-term allograft survival. J Immunol 1999;162:1947-1951.

94. Teague TK, Marrack P, Kappler JW, Vella AT. IL-6 rescues resting mouse T cells from apoptosis. J Immunol 1997;158:57915796.

95. Vella AT, Mitchell T, Groth B, et al. CD28 engagement and proinflammatory cytokines contribute to $\mathrm{T}$ cell expansion and long-term survival in vivo. J Immunol 1997;158:4714-4720.

96. Kearney ER, Walunas TL, Karr RW, et al. Antigen-dependent clonal expansion of a trace population of antigen-specific CD4+ $\mathrm{T}$ cells in vivo is dependent on CD28 costimulation and inhibited by CTLA-4. J Immunol 1995;155:1032-1036.

97. Delon J, Germain RN. Information transfer at the immunological synapse. Curr Biol 2000;10:R923-933.

98. Croft M, Bradley LM, Swain SL. Naive versus memory CD4 T cell response to antigen. Memory cells are less dependent on accessory cell costimulation and can respond to many antigen-presenting cell types including resting B cells. J Immunol 1994;152:2675-2685.

99. Howland KC, Ausubel LJ, London CA, Abbas AK. The roles of CD28 and CD40 ligand in T cell activation and tolerance. J Immunol 2000;164:4465-4470.

100. London CA, Lodge MP, Abbas AK. Functional responses and costimulator dependence of memory CD4 + T cells. J Immunol 2000;164:265-272.

101. Lovett-Racke AE, Trotter JL, Lauber J, Perrin PJ, June CH, Racke MK. Decreased dependence of myelin basic protein-reactive T cells on CD28-mediated costimulation in multiple sclerosis patients. A marker of activated/memory $\mathrm{T}$ cells. J Clin Invest 1998;101:725-730.

102. Teh HS, Teh SJ. High concentrations of antigenic ligand activate and do not tolerize naive CD4 T cells in the absence of CD28/B7 costimulation. Cell Immunol 1997;179:74-83.

103. Scholz C, Patton KT, Anderson DE, Freeman GJ, Hafler DA. Expansion of autoreactive $\mathrm{T}$ cells in multiple sclerosis is independent of exogenous B7 costimulation. J Immunol 1998;160: 1532-1538.

104. Lin H, Bolling SF, Linsley PS, et al. Long-term acceptance of major histocompatibility complex mismatched cardiac allografts induced by CTLA4Ig plus donor-specific transfusion. J Exp Med 1993;178:1801-1806.

105. Weber CJ, Hagler MK, Chryssochoos JT, et al. CTLA4-Ig prolongs survival of microencapsulated neonatal porcine islet xenografts in diabetic NOD mice. Cell Transplant 1997;6:505508 .

106. Moreland LW, Alten R, Van den Bosch F, et al. Costimulatory blockade in patients with rheumatoid arthritis: a pilot, dose-finding, double-blind, placebo-controlled clinical trial evaluating CTLA-4Ig and LEA29Y eighty-five days after the first infusion. Arthritis Rheum 2002;46:1470-1479.

107. Grohmann U, Orabona C, Fallarino F, et al. CTLA-4-Ig regulates tryptophan catabolism in vivo. Nat Immunol 2002;3: 1097-1101.

108. Satoh J, Paty DW, Kim SU. Differential effects of beta and gamma interferons on expression of major histocompatibility complex antigens and intercellular adhesion molecule-1 in cultured fetal human astrocytes. Neurology 1995;45:367-373.

109. Salomon B, Lenschow DJ, Rhee L, et al. B7/CD28 costimulation is essential for the homeostasis of the CD4+CD25+ immunoregulatory $\mathrm{T}$ cells that control autoimmune diabetes. Immunity 2000;12:431-440.

110. Tang Q, Henriksen KJ, Boden EK, et al. Cutting edge: CD28 controls peripheral homeostasis of $\mathrm{CD} 4+\mathrm{CD} 25+$ regulatory $\mathrm{T}$ cells. J Immunol 2003;171:3348-3352.

111. Kremer JM, Westhovens R, Leon M, et al. Treatment of rheumatoid arthritis by selective inhibition of T-cell activation with fusion protein CTLA4Ig. N Engl J Med 2003;349:1907-1915.

112. Kremer JM, Dougados M, Emery P, et al. Treatment of rheumatoid arthritis with the selective costimulation modulator abatacept: twelve-month results of a phase IIb, double-blind, randomized, placebo-controlled trial. Arthritis Rheum 2005;52:22632271.

113. Abrams JR, Lebwohl MG, Guzzo CA, et al. CTLA4Ig-mediated blockade of T-cell costimulation in patients with psoriasis vulgaris. J Clin Invest 1999;103:1243-1252.

114. Abrams JR, Kelley SL, Hayes E, et al. Blockade of T lymphocyte costimulation with cytotoxic $\mathrm{T}$ lymphocyte-associated antigen 4-immunoglobulin (CTLA4Ig) reverses the cellular pathology of psoriatic plaques, including the activation of keratinocytes, dendritic cells, and endothelial cells. J Exp Med 2000;192:681-694.

115. Vincenti F, Larsen C, Durrbach A, et al. Costimulation blockade with belatacept in renal transplantation. N Engl J Med 2005;353: $770-781$.

116. Arnason BG. Relevance of experimental allergic encephalomyelitis to multiple sclerosis. Neurol Clin 1983;1:765-782.

117. Koh DR, Ho A, Rahemtulla A, Penninger J, Mak TW. Experimental allergic encephalomyelitis (EAE) in mice lacking CD4+ T cells. Eur J Immunol 1994;24:2250-2253.

118. Allegretta M, Nicklas JA, Sriram S, Albertini RJ. T cells respon- 
sive to myelin basic protein in patients with multiple sclerosis. Science 1990;247:718-721.

119. Griggs ND, Agersborg SS, Noelle RJ, Ledbetter JA, Linsley PS, Tung KS. The relative contribution of the CD28 and gp39 costimulatory pathways in the clonal expansion and pathogenic acquisition of self-reactive T cells. J Exp Med 1996; 183:801-810.

120. Carayanniotis G, Masters SR, Noelle RJ. Suppression of murine thyroiditis via blockade of the CD40-CD40L interaction. Immunology 1997;90:421-426.

121. Balasa B, Krahl T, Patstone G, et al. CD40 ligand-CD40 interactions are necessary for the initiation of insulitis and diabetes in nonobese diabetic mice. J Immunol 1997;159:4620-4627.

122. Howard LM, Miga AJ, Vanderlugt CL, et al. Mechanisms of immunotherapeutic intervention by anti-CD40L (CD154) antibody in an animal model of multiple sclerosis. J Clin Invest 1999;103:281-290.

123. Nakamura M, Tanaka Y, Satoh T, et al. Autoantibody to CD40 ligand in systemic lupus erythematosus: association with throm- bocytopenia but not thromboembolism. Rheumatology (Oxford) 2006; $45: 150-156$.

124. Kelley SK, Gelzleichter T, Xie D, et al. Preclinical pharmacokinetics, pharmacodynamics, and activity of a humanized antiCD40 antibody (SGN-40) in rodents and non-human primates. Br J Pharmacol 2006;148:1116-1123.

125. Tai YT, Li X, Tong X, et al. Human anti-CD40 antagonist antibody triggers significant antitumor activity against human multiple myeloma. Cancer Res 2005;65:5898-5906.

126. Tai YT, Li XF, Catley L, et al. Immunomodulatory drug lenalidomide (CC-5013, IMiD3) augments anti-CD40 SGN-40-induced cytotoxicity in human multiple myeloma: clinical implications. Cancer Res 2005;65:11712-11720.

127. Shorts L, Weiss JM, Lee JK, et al. Stimulation through CD40 on mouse and human renal cell carcinomas triggers cytokine production, leukocyte recruitment, and antitumor responses that can be independent of host CD40 expression. J Immunol 2006;176: $6543-6552$. 